\title{
Serum ferritin, liver iron stores, and liver histology in children with thalassaemia
}

\author{
S DE VIRGILIIS, G SANNA, G CORNACCHIA, F ARGIOLU, V MURGIA, \\ $M$ PORCU, AND A CAO \\ Istituto di Clinica Pediatrica II ${ }^{\mathrm{A}}$, and Istituto di Chimica Farmaceutica, University of Cagliari, Italy
}

SUMMARY Serum ferritin, liver iron stores, and liver histology were studied in 38 children with thalassaemia major who were being treated by regular blood transfusions. There was no correlation between serum ferritin levels and either the number of transfusions or the amount of iron deposited in the liver. However, for a given level of iron stores, ferritin levels were higher in patients with chronic hepatitis (including chronic aggressive and chronic persistent forms) than in those with hepatic siderosis only. We conclude that serum ferritin reflects tissue iron deposits in regularly transfused thalassaemic patients, only in the absence of hepatitis.

Many authors have shown that serum ferritin concentration reflects body iron stores. ${ }^{1-2}$ Moreover there is a direct correlation between the units of blood transfused and serum ferritin levels in patients with transfusion siderosis. ${ }^{2-3}$ On the other hand, Lipschitz et al. ${ }^{2}$ and Prieto et al. ${ }^{4}$ found raised serum ferritin levels in patients with both acute and chronic hepatitis, the values being particularly high in patients with viral hepatitis or drug-induced liver necrosis. Jacobs ${ }^{5}$ stated that there were insufficient data for using serum ferritin as an index for liver injury. Therefore, the use of ferritin determinations clinically should be confined to providing a simple and noninvasive way to evaluate body iron stores.

Earlier studies (unpublished) showed, as did the findings of Masera et al., ${ }^{6}$ that many regularly transfused patients with $\beta$-thalassaemia major are affected by chronic persistent hepatitis ( $\mathrm{CPH})$ and chronic aggressive hepatitis (CAH). We hoped to establish whether serum ferritin determination is a valid method for iron overload assessment in regularly transfused patients with a high incidence of chronic hepatitis.

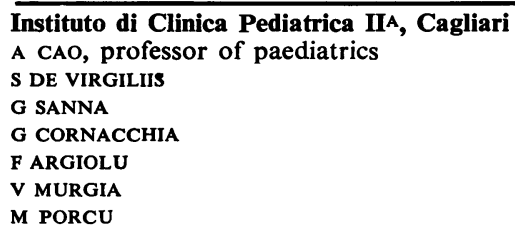

\section{Materials and methods}

We examined $36 \beta^{\circ}$-thalassaemia homozygotes aged between 6 and 10 years. The histopathological findings showed that 12 of them had CPH, 18 had $\mathrm{CAH}$, and 6 had siderosis. The diagnosis of homozygous $\beta^{\circ}$-thalassaemia was made on the basis of $\mathrm{Hb}$ electrophoresis and globin chain synthesis. ${ }^{7}$

For the last 3 years patients have been transfused about every 3 or 4 weeks with packed red cells to keep $\mathrm{Hb}$ pretransfusion level $>7 \mathrm{~g} / \mathrm{dl}$ (with mean annual $\mathrm{Hb}$ level $9.45 \mathrm{~g} / \mathrm{dl}$ ). Desferrioxamine was given IM, $750 \mathrm{mg} /$ day to children between 3 and 9 years and $1 \mathrm{~g}$ /day to children over 9 years for six days a week. Previously, the patients had received only occasional transfusions, and desferrioxamine had been administered in low doses and irregularly.

The histopathological diagnosis on biopsy specimens followed the criteria of De Groote et al. ${ }^{8}$ modified by Bianchi et al. ${ }^{9}$ Diagnosis of chronic persistent hepatitis was thereby based on chronic inflammatory infiltration, mostly portal, with preserved lobular architecture and little or no fibrosis; piecemeal necrosis was absent or slight. The criteria for chronic active hepatitis were a chronic inflammatory and fibrosing lesion characterised by piecemeal necrosis, new fibre formation, and lymphocytic infiltration of portal tracts and lobules, or chronic hepatitis with bridging necrosis.

In our department, patients who have persistently ( $>6$ months) raised serum transaminases (thrice normal) undergo liver biopsy. Those with excessive 
transfusion needs (transfusion quotient above 2$)^{10}$ are splenectomised. A biopsy specimen is routinely taken in the course of such surgery.

Liver biopsy tissue is cut in two: one part is used for histopathology. The iron content of the other is determined as follows: the dry sample is incinerated in a muffle oven at $600^{\circ} \mathrm{C}$; the ashes are dissolved in $3 \mathrm{ml}$ concentrated $\mathrm{HCl}$ and brought to $100 \mathrm{ml}$ with deionised $\mathrm{H}_{2} \mathrm{O}$. Iron-free glassware and solutions are used throughout. A Perkin-Elmer model 503 spectrophotometer with atomic absorption is used for iron determination; the flame technique is followed for iron solutions $>0.1 \mathrm{mg} / 1$ and the graphite oven technique (using model HGA 2100) for lower concentrations.

The patient's serum obtained just before liver biopsy is used for serum iron determination. Serum ferritin concentration is measured in duplicate samples of venous blood as ferritin protein using the immunoradiometric assay technique of Addison et al. ${ }^{11}$ modified by Miles et al. ${ }^{12}$

\section{Results}

Fig. 1 shows the serum ferritin levels related to the number of transfusions the patients received (units of blood transfused). There was no correlation between serum ferritin levels and the number of transfusions received, even in cases of simple siderosis $(r=0 \cdot 176 ; P=N S)$.

Fig. 2 shows serum ferritin levels in patients with differing liver histopathology: there was a highly significant difference $(P<0 \cdot 001)$ between the mean serum ferritin level in patients with simple siderosis compared with those with CPH and CAH. Moreover patients with CAH had higher levels than those with $\mathrm{CPH}(\mathrm{P}<0 \cdot 001)$, while there was no significant difference between patients with simple siderosis and those with $\mathrm{CPH}$.

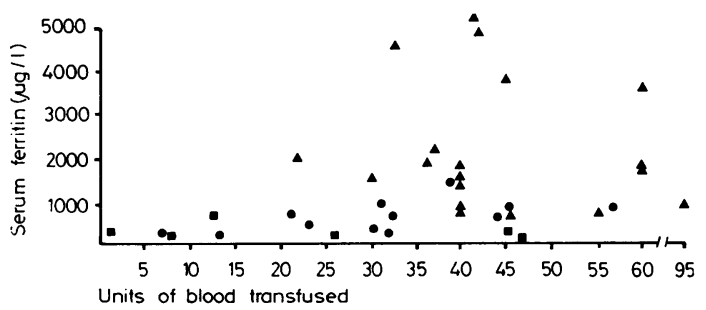

Fig. 1 Serum ferritin in regularly transfused thalassaemic children with and without chronic hepatitis: relation with the number of transfused units $(r=0 \cdot 176$; $N S)$. Siderosis ( $\square)$, chronic persistent hepatitis $(C P H)$ $(\bullet)$, chronic aggressive hepatitis $(C A H)(\Delta)$.

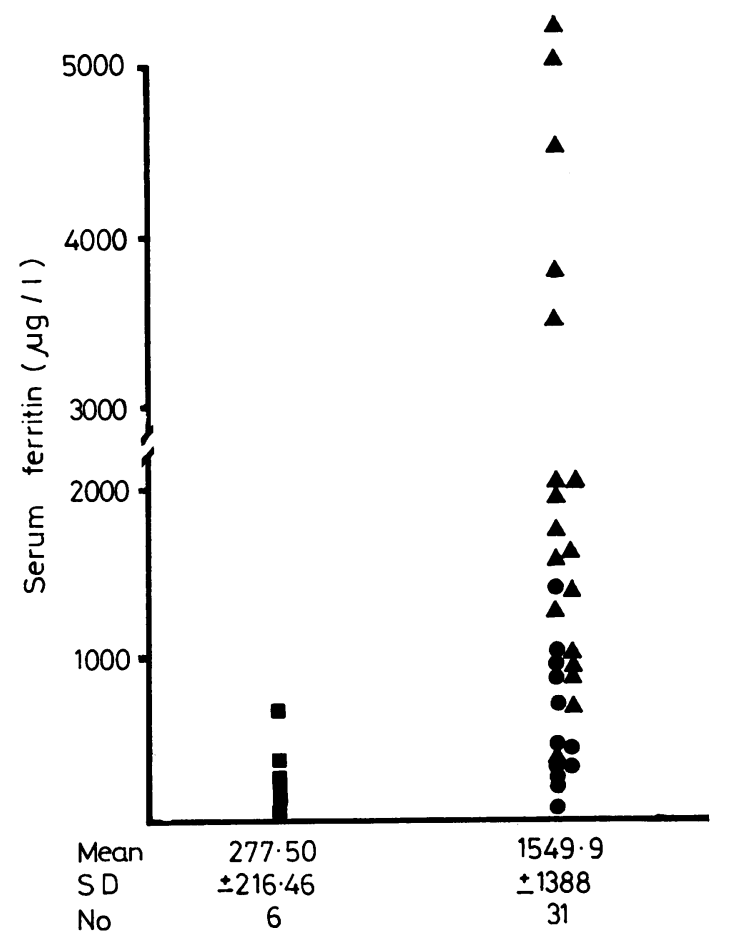

Fig. 2 Serum ferritin in regularly transfused thalassaemic children related to liver histopathology $(F=10 \cdot 74, P<0.001$ by analysis of variance).

Siderosis ( $(\square)$, versus chronic persistent hepatitis $(\mathrm{CPH})(\bullet)$, and chronic aggressive hepatitis $(\mathrm{CAH})(\Lambda)$.

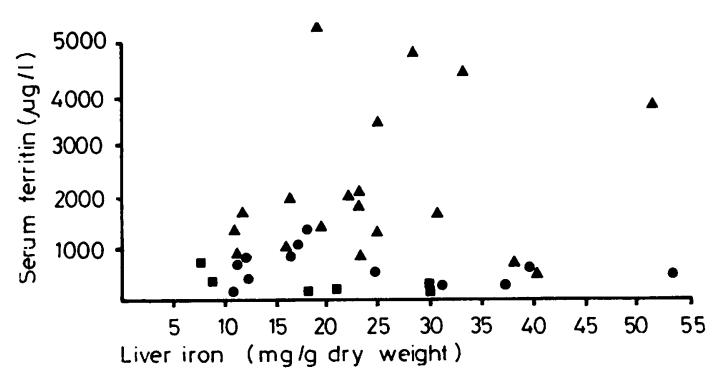

Fig. 3 Serum ferritin levels and liver iron concentrations in regularly transfused thalassaemic children $(r=0 \cdot 159 ; N S)$. Siderosis $(\square)$, chronic persistent hepatitis $(\mathrm{CPH})(\bullet)$, chronic aggressive hepatitis $(C A H)(\Lambda)$.

Fig. 3 shows the levels of serum ferritin and iron in liver tissue. The progressive rise of serum ferritin levels from siderosis to $\mathrm{CPH}$ and from $\mathrm{CPH}$ to $\mathrm{CAH}$ with the same iron concentration in the tissue can be seen. 


\section{Discussion}

We found no correlation between serum ferritin levels and either the number of transfusions received, or the amount of liver iron in patients with thalassaemia major and chronic hepatitis. This is contrary to the findings of Letsky et al. ${ }^{3}$ One reason for this might be that our patients had had irregular and low transfusions before this 3-year study, perhaps leading to an irregular and high intestinal absorption of iron. A second explanation might be that our patients had not all followed the chelation treatment with desferrioxamine in the same way. However, these explanations scarcely account for the lack of correlation between serum ferritin and liver iron. Yet if liver histopathology is also taken into account, with an equal iron concentration in the liver, serum ferritin levels are significantly higher in patients with CAH and CPH than in those with simple liver siderosis.

In our patients with chronic hepatitis, serum ferritin levels did not seem to reflect iron overload. There may be two reasons for these high levels: (1) Leakage from the injured liver cells. Prieto et al. ${ }^{4}$ studied a group of patients with acute and chronic liver diseases and found the highest ferritin levels in patients with massive liver necrosis. (2) Increased ferritin synthesis. Such an increase was found by Konijn and Hershko ${ }^{13}$ when they injected rats with turpentine.

Our data show that serum ferritin levels reflect body iron stores only in regularly transfused patients in whom there has been no acute or chronic hepatitis. The only other method to evaluate body iron stores is by way of a liver biopsy specimen.

In any event, when serum ferritin is greatly increased, whatever the reason, there is cause for concern and increasingly aggressive iron chelation treatment should be given.

We are grateful to Vera Pegna who translated the paper, and to Rita Loi for editorial assistance.
This work was supported by research grants from CNR contract number 770062686, Regione Autonoma della Sardegna and Sindacato Lavoratori Bancari.

\section{References}

1 Jacobs A, Miller F, Worwood M, Beamish M R, Wardrop C A. Ferritin in the serum of normal subjects and patients with iron deficiency and iron overload. $\mathrm{Br}$ Med J 1972; 4: 206-8.

2 Lipschitz D A, Cook J D, Finch C A. A clinical evaluation of serum ferritin as an index of iron stores. $N$ Engl J Med 1974; 290 : 1213-6.

${ }^{3}$ Letsky E A, Miller F, Worwood M, Flynn D M. Serum ferritin in children with thalassaemia regularly transfused. $J$ Clin Pathol 1974; 27 : 652-5.

4 Prieto J, Barry M, Sherlock J. Serum ferritin in patients with iron overload and with acute and chronic liver diseases. Gastroenterology 1975; 68: 525-33.

5 Jacobs A. Serum ferritin and iron stores. Fed Proc 1977; 36: 2024-7.

- Masera G, Jean G, Gazzola G, Novakova M. Role of chronic hepatitis in development of thalassaemic liver diseases. Arch Dis Child 1976; 51: 680-5.

7 Kan Y W, Schwartz E, Nathan D G. Globin chain synthesis in the alpha-thalassemia syndromes. $J$ Clin Invest 1968; 47: 2515-22.

8 De Groote J, Desmet V J, Gedigk P, et al. A classification of chronic hepatitis. Lancet 1968; 2 : 626-8.

9 Bianchi L, De Groote J, Desmet V J, et al. Acute and chronic hepatitis revisited. Lancet 1977; 2: 914-9.

10 Modell C B. Total management of thalassaemia major. Arch Dis Child 1977; 52: 489-500.

11 Addison G M, Beamish M R, Holes C M, Hodgkins M, Jacobs A, Llewellin P. An immunoradiometric assay for ferritin in the serum of normal subjects and patients with iron deficiency and iron overload. J Clin Prthol 1972; 25: 326-9.

12 Miles L E M, Lipschitz D A, Bieber C P, Cook J D. Measurement of serum ferritin by 2 site immunoradiometric assay. Anal Biochem 1974; 61: 209-24.

13 Konijn A M, Hershko C. Ferritin synthesis in inflammation. Br J Haematol 1977; 37: 7-16.

Correspondence to Professor Antonio Cao, Clinica Pediatrica II A Università, Via Porcell 1, 09100 Cagliari, Sardinia, Italy.

Received 12 December 1978 